\title{
Interaction of Polynucleotide in Aqueous NaCl Solution. III. Poly(riboadenylic acid)-Poly(riboinosinic acid) System
}

\author{
Kazuhiko FujIoKA, Yoshihiro BABA, Akihiro Kagemoto, * \\ and Ryoichi FUJISHIRO \\ Department of General Education, Osaka Institute of Technology, \\ 16-1, 5-chome, Asahi-ku, Osaka 535, Japan.
}

(Received April 8, 1980)

\begin{abstract}
KEY WORDS Poly(riboadenylic acid) / Poly(riboinosinic acid) / Heat of Interaction / $\mathrm{NaCl}$ Concentration Dependence / Poly(riboadenylic acid) $\cdot$ Poly(2 riboinosinic acid) Triplex /
\end{abstract}

It is well known that deoxyribonucleic acid (DNA) forms the double helical structure by the interaction between the bases: purine and pyrimidine.

In order to obtain thermodynamic information about the formation of this double helix, we measured the enthalpy change in the complex formation between synthetic polynucleotides such as poly(riboadenylic acid) (poly(A)) and poly(ribouridylic acid) (poly(U)), ${ }^{1,2}$ poly(riboguanylic acid) (poly $(G))$ and poly(ribocytidylic acid) (poly$(\mathrm{C})){ }^{3}$ and poly(riboinosinic acid) (poly(I)) and poly $(\mathrm{C}),{ }^{4}$ and showed that the enthalpy change in this formation depends on the chemical structure of the base of a polynucleotide and the microscopic medium surrounding the polynucleotide, such as an $\mathrm{NaCl}$ concentration. Hitherto, there has been no information on the behavior of $\operatorname{poly}(\mathrm{A})$ and poly(I) in solution.

In this paper, in order to obtain further information about the effect of chemical structure on the enthalpy change of base pairing in nucleotides, we measured the heat of mixing of poly(A)-poly(I) system.

\section{EXPERIMENTAL}

\section{Materials}

Poly(riboadenylic acid), poly(A), and poly(riboinosinic acid), poly(I), were purchased from

\footnotetext{
* To whom correspondence should be addressed.
}

Miles Lab., USA and used without further purification. The $\mathrm{NaCl}$ used in this study was the analytical reagent grade of commercial products. All measurements were made in $0.1 \mathrm{~mol} \mathrm{dm}^{-3}$ Tris$\mathrm{HCl}$ buffer solution ( $\mathrm{pH} 7.60)$. The concentration of nucleotide phosphate was determined by the phosphorous analysis method. ${ }^{5}$

\section{Apparatus and Procedure}

The calorimeter used was the same as that described in a previous paper. ${ }^{3}$ For measuring the heat of mixing of poly(A) and poly(I) solutions containing various concentrations of $\mathrm{NaCl}$, the concentration of nucleotide was made to be about $6 \times 10^{-4} \mathrm{~mol} \mathrm{dm}^{-3}$ and equal volumes $\left(1 \mathrm{~cm}^{3}\right)$ of those solution were mixed.

Ultraviolet (UV) and circular dichroism (CD) spectra were measured by a spectrophotometer (Hitachi 124, Hitachi Ltd., Japan) and a spectropolarimeter (J-20, JASCO, Japan). In this case, the UV and CD spectra of a mixture of poly(A) and poly(I) solutions were measured within $10 \mathrm{~min}$ after mixing. The poly(A) and poly(I) concentrations for the spectrophotometric measurements were about onesixth those of the calorimetric ones.

\section{RESULTS AND DISCUSSION}

The heats of mixing of an equimolar mixture of poly(A) and poly(I) in solution at various $\mathrm{NaCl}$ concentrations were measured by a microcalorimeter at $298 \pm 0.002 \mathrm{~K}$. The results obtained are 


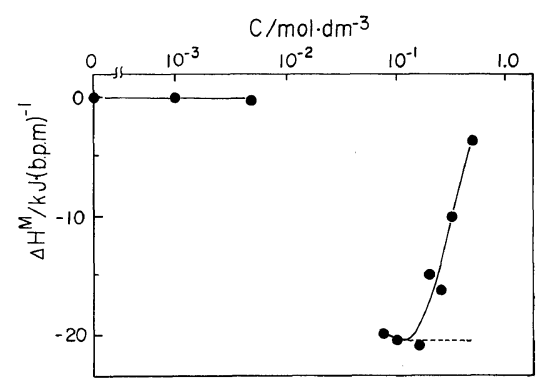

Figure 1. The heats of mixing of an equimolar mixture of $\operatorname{poly}(\mathrm{A})$ and $\mathrm{Poly}(\mathrm{I})$ in $0.1 \mathrm{moldm}^{-3}$ Tris- $\mathrm{HCl}$ solution $(\mathrm{pH} 7.60)$ at various $\mathrm{NaCl}$ concentrations at $298 \mathrm{~K}$.

shown in Figure 1, where the heats of mixing per mole of base pair (bpm) of poly(A) and poly(I), $\Delta H^{\mathrm{M}}$, is plotted against the $\mathrm{NaCl}$ concentration of the solution. As seen in Figure $1, \Delta H^{\mathrm{M}}$ is nearly zero when the $\mathrm{NaCl}$ concentration is less than about $0.005 \mathrm{~mol} \mathrm{dm}^{-3}$, demonstrating that no interaction between poly(A) and poly(I) exists under this condition.

With a $\mathrm{NaCl}$ concentration greater than $0.1 \mathrm{~mol}$ $\mathrm{dm}^{-3}, \Delta H^{\mathrm{M}}$ was exothermic and showed a definite value in the vicinity of $0.1 \mathrm{~mol} \mathrm{dm}^{-3} \mathrm{NaCl}$ and increased sharply as the concentration of $\mathrm{NaCl}$ increased. Therefore, $\Delta H^{\mathrm{M}}$ may correspond to the heat of interaction, going on the assumption that the heat of dilution of the polymer is negligibly small.

In addition, $\Delta H^{\mathrm{M}}$, in a $\mathrm{NaCl}$ concentration range from 0.01 to $0.05 \mathrm{~mol} \mathrm{dm}^{-3}$, could not be estimated because the exothermic curve areas of the reaction runs for mixing of poly(A) and poly(I) were negligibly small, compared with the sharp exothermic curves obtained when the concentration of
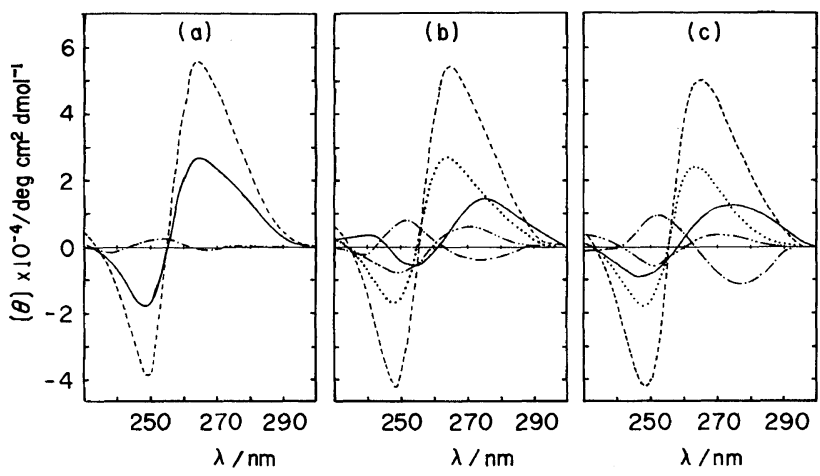

Figure 2. CD spectra of poly(A) (----), poly(I) (-- -), and an equimolar mixture of poly(A) and poly(I) $(-)$ in solution at various $\mathrm{NaCl}$ concentration: (a), $0.01 \mathrm{~mol} \mathrm{dm}^{-3}$; (b), $0.1 \mathrm{~mol} \mathrm{dm}^{-3} ;$ (c), 0.3 mol dm ${ }^{-3}$. The dotted line $(\cdots \cdots)$ is the CD curve synthesized by adding the CD spectra of only poly(A) to those of only poly(I). The broken line (_ _- ) represents the CD spectra of an equimolar mixture of poly(A) and poly(I) at $353 \mathrm{~K}$.

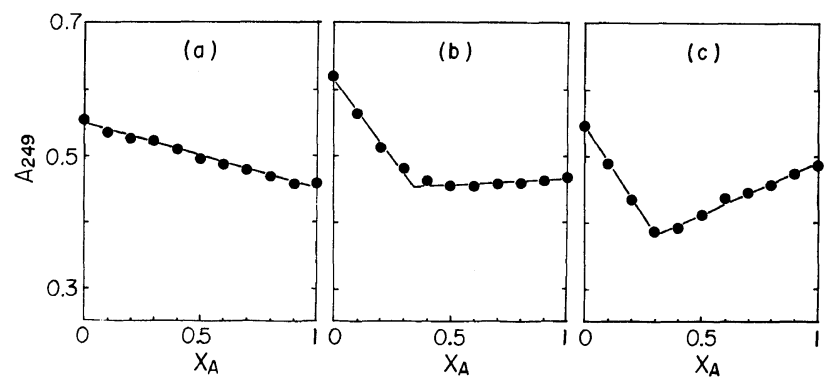

Figure 3. The plots of absorbance at $249 \mathrm{~nm}$ against the mole fraction of poly(A), $X_{\mathrm{A}}$, for mixtures of poly(A) and poly(I) in solutions at various $\mathrm{NaCl}$ concentrations: (a), $0.01 \mathrm{~mol} \mathrm{dm}^{-3}$; (b), $0.1 \mathrm{~mol} \mathrm{dm}^{-3}$; (c), $0.3 \mathrm{~mol} \mathrm{dm}^{-3}$. 
$\mathrm{NaCl}$ was in excess of $0.1 \mathrm{~mol} \mathrm{dm}^{-3}$.

$\Delta H^{\mathrm{M}}$ is negligibly small in a $\mathrm{NaCl}$ concentration range from 0.01 to $0.05 \mathrm{~mol} \mathrm{dm}^{-3}$, and this seems to be due to the following reason. Rich ${ }^{6}$ reported that the formation of $\operatorname{poly}(\mathrm{A}) \cdot \operatorname{poly}(\mathrm{I})$ or poly(A) $\operatorname{poly}(2 \mathrm{I})$ complexes is controlled by the ionic strength of medium, and at a low ionic strength, only the $1: 1$ complex forms after $18 \mathrm{~h}$. From the results by Rich and those obtained in our present work, we suggest that poly(I) having a random-coil state may need additional time to form a complex with poly(A) in a dilute $\mathrm{NaCl}$ solution.

To clarify the formation of the $1: 1$ complex at very low ionic strength, further study will be necessary.

In order to confirm the interaction between poly(A) and poly(I), the CD spectra of various mixture of poly(A) and poly(I) in solution were measured. The results obtained are shown in Figure 2. As seen in Figure 2, the $C D$ spectra of an equimolar mixture of poly(A) and poly(I) in a solution containing 0.1 and $0.3 \mathrm{~mol} \mathrm{dm}^{-3} \mathrm{NaCl}$ differ from the spectrum in a $0.01 \mathrm{~mol} \mathrm{dm}^{-3} \mathrm{NaCl}$ solution which is the same as that synthesized by adding the CD spectrum of only poly(I) to that of only poly(A) at room temperature, and also differ from the CD spectra of an equimolar mixture of poly(A) and poly(I) at $353 \mathrm{~K}$. This suggests that in an equimolar mixture of poly(A) and poly(I) in a 0.1 and $0.3 \mathrm{~mol} \mathrm{dm}^{-3} \mathrm{NaCl}$ solution there is some interaction between poly(A) and poly(I).

In order to confirm the interaction in an equimolar mixture of poly(A) and poly(I) in a concentrated $\mathrm{NaCl}$ solution exceeding $0.1 \mathrm{~mol}$ $\mathrm{dm}^{-3}$, the absorbances at $249 \mathrm{~nm}$ for various mole fractions of poly(A), $X_{\mathrm{A}}$, were measured and the results obtained are plotted against $X_{\mathrm{A}}$, as shown in Figure 3.

As shown in Figure 3, the absorbance mixing curves for $\mathrm{NaCl}$ solutions of 0.1 and $0.3 \mathrm{~mol} \mathrm{dm}^{-3}$ show discontinuous points which do not appear in the absorbance mixing curve for $0.01 \mathrm{~mol} \mathrm{dm}^{-3}$ $\mathrm{NaCl}$ solution. These discontinuous points appearing in the vicinity of 0.3 of $X_{\mathrm{A}}$ correspond to the some interaction between poly(A) and poly(I), demonstrating that this interaction is based on the formation of a triple stranded helical structure of $\operatorname{poly}(\mathrm{A}) \cdot \operatorname{poly}(2 \mathrm{I})$.

To obtain information about the poly(A). poly(2I) triplex, plots were made of molar ellipli-

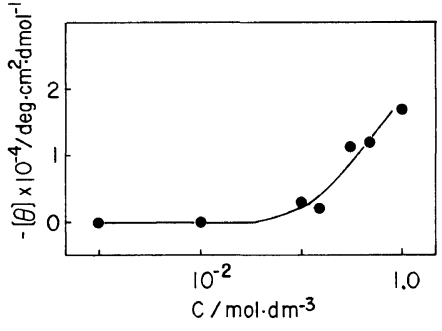

Figure 4. Dependence of molar elliplicity at $277 \mathrm{~nm}$ of poly(I) solution on $\mathrm{NaCl}$ concentration.

city at $277 \mathrm{~nm}$ of $\mathrm{CD}$ spectra against $\mathrm{NaCl}$ concentration. And these seem to reflect the extent of the ordered structure of poly(I), as shown in Figure 4.

Figure 4 shows that the intensity is nearly zero when the $\mathrm{NaCl}$ concentration is below $0.1 \mathrm{~mol} \mathrm{dm}^{-3}$ and that this intensity begins to increase when the $\mathrm{NaCl}$ concentration exceeds $0.1 \mathrm{moldm}^{-3}$. This increase in intensity indicates that poly(I) can form an ordered structure such as a triple or quadruple stranded structure ${ }^{7,8}$ at a $\mathrm{NaCl}$ concentration above $0.1 \mathrm{~mol} \mathrm{dm}^{-3}$. On the other hand, CD spectra of poly(A) are independent of $\mathrm{NaCl}$ concentration, as seen in Figure 2.

These facts are interpreted as follows: at a $\mathrm{NaCl}$ concentration below $0.1 \mathrm{~mol} \mathrm{dm}^{-3}$, no complex will form between poly(A) and poly(I) having a randomcoil state under our experimental conditions. On the other hand, in the concentrated $\mathrm{NaCl}$ solution, a complex, poly(A) - poly(2I) triplex will be formed, indicating that the interaction between poly(A) and poly(I) is stronger than that between poly(I) and poly(I). The formation of poly(A) - poly(2I) triplex by mixing of poly(A) and poly(I) may be due to the following reactions,

$$
\begin{aligned}
\operatorname{poly}(\mathrm{A}) & +\operatorname{poly}(\mathrm{I})(\text { order }) \\
& \stackrel{\Delta H_{\mathrm{t}}}{\longrightarrow} \operatorname{poly}(\mathrm{A})+\operatorname{poly}(\mathrm{I})(\text { disorder }) \\
& \stackrel{\Delta H}{\longrightarrow} 1 / 2 \operatorname{poly}(\mathrm{A}) \cdot \operatorname{poly}(2 \mathrm{I})+1 / 2 \operatorname{poly}(\mathrm{A})
\end{aligned}
$$

where poly(I) (order) and poly(I) (disorder) refer to the triple or quadruple stranded structure and random-coil state, respectively. Thus, $\Delta H^{\mathrm{M}}$ can be represented as the sum of the heats of the orderdisorder transition of poly(I), $\Delta H_{t}$, and the heat of formation of the poly(A) $\operatorname{poly}(2 \mathrm{I})$ triplex, $\Delta H$, 


$$
\Delta H^{\mathrm{M}}=\Delta H_{\mathrm{t}}+\Delta H
$$

$\Delta H_{\mathrm{t}}$ is equal to zero since the triple or quadruple stranded structure of poly(I) does not exist in 0.1 mol dm ${ }^{-3} \mathrm{NaCl}$ solution, according to $\mathrm{CD}$ spectra results obtained, and so $\Delta H$ becomes equal to $\Delta H^{\mathrm{M}}$. The $\Delta H$ calculated as the value per mole of base pair must be converted to the $\Delta H$ value per mole of base triplet according to the reaction 1, and consequently, $\Delta H$ is obtained as about $-42 \mathrm{~kJ}$ per mole of base triplet in aqueous $0.1 \mathrm{~mol} \mathrm{dm}^{-3} \mathrm{NaCl}$ solution.

Furthermore, $\Delta H^{\mathrm{M}}$ increases when the $\mathrm{NaCl}$ concentration is more than $0.1 \mathrm{~mol} \mathrm{dm}^{-3}$, as seen in Figure 1. This increase of $\Delta H^{\mathrm{M}}$ corresponds to an increase in the apparent heat of transition of poly(I) (order) because the extent of structure of poly(I) depends on the $\mathrm{NaCl}$ concentration. This extent, however, was not estimated since the dependence of the heat of transition of poly(I) on the $\mathrm{NaCl}$ concentration was not estimated in this work.

\section{REFERENCES}

1. S. Tanaka, Y. Baba, and A. Kagemoto, Polym. J., 8, 325 (1976).

2. Y. Baba, S. Tanaka, and A. Kagemoto, Makromol. Chem., 178, 2112 (1977).

3. Y. Baba, K. Fujioka, and A. Kagemoto, Polym. J., 10, 241 (1978).

4. K. Fujioka, Y. Baba, A. Kagemoto, and R. Fujishiro, Polym. J., 12, 843 (1980).

5. P. S. Chen, T. Y. Toribaya, and H. Warner, Anal. Chem., 28, 1755 (1956).

6. A. Rich, Nature, 181, 521 (1958).

7. A. Rich, Biochim. Biophys. Acta, 29, 502 (1958).

8. S. Arnott, R. Chandrasekaran, and C. M. Marttila, Biochem. J., 141, 537 (1974). 